\title{
Technical Analysis of Food And Beverage Sector Stocks in JII
}

\author{
${ }^{1}$ Annuridya Rosyidta Pratiwi Octasylva \\ ${ }^{1}$ Faisal Fachroji \\ Program Studi Manajemen, Institut Teknologi Indonesua
annuridya@yahoo.com ${ }^{1,}$
ffachroji@gmail.com ${ }^{2,}$
}

\begin{abstract}
ABSTRAK
Investasi merupakan upaya menanamkan dana untuk dikembangkan dalam jangka waktu yang telah ditentukan untuk mendapatkan keuntungan. Investasi bisa dilakukan melalui sektor rill, maupun non rill. Pada penelitian ini akan membahas investasi sektor non rill terutama di pasar modal yang sudah jelas return dan kemanannya, yang akan berfokus pada saham. JII (Jakata Islmaic Index) adalah 30 saham syariah yang paling liquid di BEI. Terdapat empat saham sektor food and beverage, seperti ICBP, INDF, JPFA, dan UNVR. analisis teknikal menggunakan historis harga dari suatu perusahaan atau saham itu sendiri, yang berasumsi bahwa itu dapat merefleksikan harga dimasa depan, biasanya yang menggunakan analisis teknikal adalah investor jangka pendek, jangka pendek disini adalah mereka para tradder yang aktif berdagang saham. Grafik adalah indikator utama untuk analisis teknikal, terutama grafik candlestick karena grafik ini mampu menampilkan pergerakan harga secara menyeluruh. Resistance adalah keadaan dimana harga sulit bergerak lebih tinggi, sedangkan support adalah kebalikannya yaitu harga sudah sulit untuk lebih rendah, kedua garis batas ini digunakan sebagai pengambil keputusan dalam analisis teknikal. Pendekatan yang biasa dilakukan adalah menggunakan pendekatan fibonacci dan umunya dibantu lagi oleh stochastic oscillator untuk menunjukan posisi closing relatif pada suatu periode. Saham ICBP dilihat dari hasil fibonacci dan indikator stochastic oscillator yang menunjukan saham ICBP mendekati resistance dan stochastic oscillator berada pada titik 70 normal zone tetapi mulai mendekati zona overbought yaitu melewati titik 80 .
\end{abstract}

Kata kunci : : Investasi, Analisis Teknikal, Fibonnaci, Support, Resistance, Stochastic Oscillator

\section{ABSTRACT}

Investment is an effort to invest funds to be developed within a predetermined period of time to get profits. Investment can be made through the rill sector, or non-rill. In this research will discuss nonrill sector investments, especially in capital markets that are clearly return and security, which will focus on stocks. JII (Jakata Islmaic Index) is the 30 most liquid Shariah stocks in IDX. There are four stocks in the food and beverage sector, such as ICBP, INDF, JPFA, and UNVR. Technical analysis is an analysis that uses the historical price of a company or share itself, which assumes that it can reflect future prices, usually those who use technical analysis are short-term investors, the short-term here are those traders who actively trade stocks. The chart is the main indicator for technical analysis, especially the candlestick chart because it is able to display overall price movements. Resistance is a situation where prices are difficult to move higher, while support is the opposite, that is, prices are difficult to lower, these two boundary lines are used as decision makers in technical analysis. The usual approach is to use a Fibonacci approach and generally aided by a stochastic oscillator to show the relative closing position of a period. ICBP shares can be seen from the results of the Fibonacci and stochastic oscillator indicators which show ICBP shares are approaching resistance and the stochastic oscillator is at the 70 point of normal zone but is starting to approach the overbought zone which is past the 80 point.

Key word: Investment, Technical Analysis, Fibonnaci, Support, Resistance, Stochastic Oscillator. 


\section{PENDAHULUAN}

Investasi merupakan upaya menanamkan dana yang dilakukan oleh investor dalam berbagai bidang usaha untuk dikembangkan dalam jangka waktu yang telah ditentukan untuk mendapatkan keuntungan (Rahmawati et al., n.d.). Investasi bisa dilakukan melalui sektor rill, maupun non rill. Sektor rill adalah investasi yang ada bentuk nyatanya, seperti emas, rumah, tanah, perkebunan, dan lain-lain. Sedangkan investasi non rill adalah investasi yang tidak ada wujudnya, seperti instrumen keuangan seperti saham, obligasi, forex, dan lain-lain. Di era globalisasi seperti sekarang investasi sektor non rill mulai mewabah, seperti saham, reksadana, bahkan hingga forex.(Rahmawati et al., n.d.) . Perkembangan investasi asset non rill dalam hal ini saham memiliki perkembangan yang cukup baik (Riska Farisa et al., 2019) dan di tandai dengan nilai indeks yang ada dai pasar modal Indonesia (Indeks Harga Saham Gabungan (IHSG), LQ45, Jakarta Islamic Index (JII), dan Indeks Saham Syariah Indonesia (ISSI)) mengalami peningkatan.

JII (Jakarta Islamic Index) merupakan indeks yang dikeluarkan oleh BEI yang berisi 30 saham syariah yang paling liquid. Terdapat empat saham sektor food and beverage yang ada di LQ45 dan juga JII seperti ICBP, INDF, JPFA, dan UNVR. Selain dengan menggunakan indeks, memilih saham juga dapat dilakukan dengan menggunakan analisis. Terdapat dua analisis yang umum dilakukan oleh para investor untuk menentukan saham mana yang akan ;mereka pilih, yaitu analisis fundamental dana analisis teknikal. Analisis fundamental adalah analisis yang biasa digunakan oleh investor jangka panjang, karna analisis ini berfokus pada kinerja perusahaan, dan menilai keberlangsungan hidup perusahaan secara luas. Sedangkan analisis teknikal adalah analisis yang menggunakan historis harga dari suatu perusahaan atau saham itu sendiri, yang berasumsi bahwa itu dapat merefleksikan harga dimasa depan, biasanya yang menggunakan analisis teknikal adalah investor jangka pendek, jangka pendek disini adalah mereka para tradder yang aktif berdagang saham. Grafik adalah indikator utama untuk analisis teknikal, terutama grafik candlestick karana grafik ini mampu menampilkan pergerakan harga secara menyeluruh. Terdapat juga garis batas, atau sering juga disebut resistance dan support. Resistance adalah keadaan dimana harga sudah sulit untuk bergerak lebih tinggi, sedangkan support adalah kebalikannya yaitu harga sudah sulit untuk lebih rendah, kedua garis batas ini digunakan sebagai pengambil keputusan dalam analisis teknikal. Pendekatan yang biasa dilakukan adalah menggunakan pendekatan fibonacci dan umunya dibantu lagi oleh stochastic oscillator untuk menunjukan posisi closing relatif pada suatu periode(BHANDARI, 2014; Bortner \& Peterson, 2016; Fisher \& Fisher, 2003; Mohammad. Alalaya, 2020; Ramlall, 2016). 
Analisis yang meramalkan harga saham dengan menggunakan harga dan volume adalah analisis teknikal(Ardani et al., 2011)Analisis teknikal juga merupakan metode estimasi pengambilan keputusan dengan menggunakan historis harga. Kondisi dimana harga saham sulit untuk turun lagi, diyakini banyak pembeli saham pada level ini, disebut juga Level support. Sedangkan kondisi haraga saham sulit untuk naik lagi, diyakini banyak penjual saham pada level ini disebut dengan level resistance. Grafik adalah indikator utama untuk analisis teknikal, terutama grafik candlestick karana grafik ini mampu menampilkan pergerakan harga secara menyeluruh. Untuk dapat melihat gambaran candle stick dapat dilihat pada gambar 1.

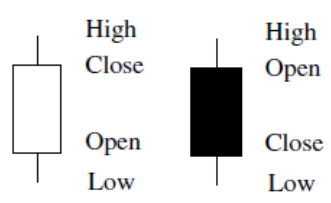

Gambar 1. Bentuk Grafik Candlestick dan Bagian-bagiannya

(Sumber: Marshall: 2006) (Marshall et al., 2006)

Berdasarkan latar belakang masalah diatas, maka penulis merumuskan masalah bagaimana analisa teknikal pada saham Food and Baverage pada saham yang terdaftar di JII (Jakarta Islamic Index)

\section{METODE PENELITIAN}

Penelitian ini merupakan penelitian kualitatif dimana subjek penelitian merupakan saham Food and Baverage yang terdaftar di JII.Adapunn flowchart penelitian ini dapat dilihat dari gambar 2 . 


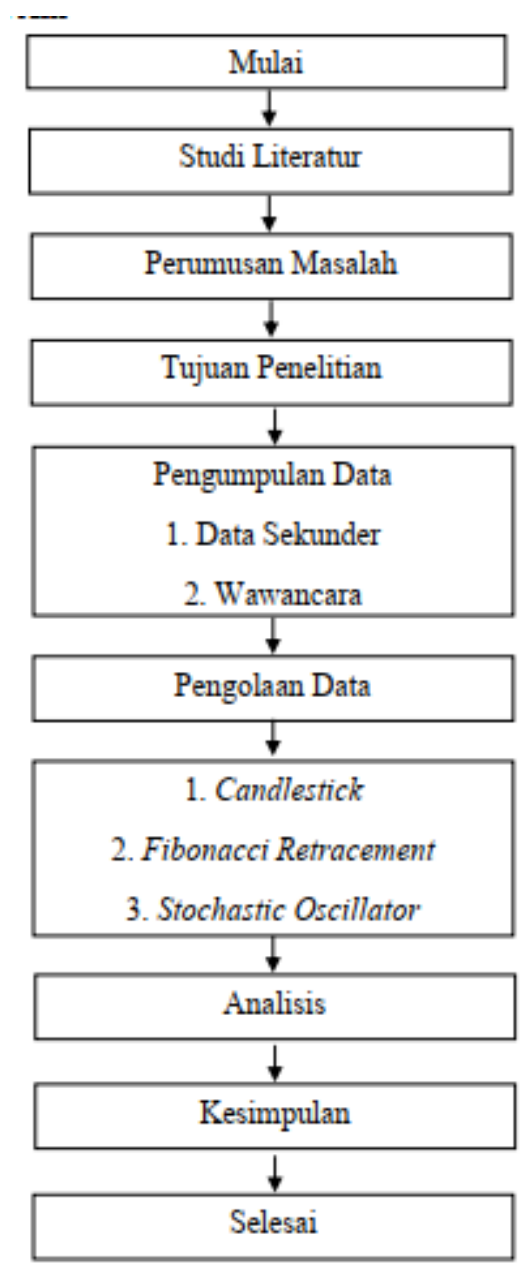

Gambar 2. Flow chart penelitian

\section{Pengumpulan data}

Data Sekunder

Penelitian ini menggunakan data yang didapat dari hasil pengamatan pergerakan harga saham individual sektor saham Food and Beverage yang terdaftar pada indeks JII 45 periode 2020. Proses pengamatan dilakukan dengan menggunakan software atau aplikasi ipotstock dari Indopremier. Pengamatan dilakukan secara on-line melalu aplikasi ipotstock tersebut sehingga pengamatan dapat dilakukan dimana saja . Penelitian ini menggunakan beberapa jenis variabel, yaitu:

1. Variabel Diskrit yaitu variabel 2 kutup berlawanan terdiri dari uptrend dan downtrend. 2. Variabel Independen yaitu variabel yang mempengaruhi atau yang menjadi sebab perubahan atau timbulnya variabel dependen (terikat). terdiri Swing High dan Swing Low. 3. Variabel Dependen yaitu variabel yang dipengaruhi atau akibat karena adanya variabel bebas. terdiri Level Support dan Level Resistance. 
4. Variabel Kontinum Ordinal yaitu variabel tingkatan terdiri Rekomendasi Keputusan Investasi.

Adapun variable penelitian dan jenis data yang disajikan dapat dilihat pada table 1 .

Tabel 1. Variable penelitian dan jenis data

\begin{tabular}{|c|c|c|c|c|}
\hline No. & Variabel & Definisi & Indikator & $\begin{array}{l}\text { Skala } \\
\text { Data }\end{array}$ \\
\hline 1. & Trend & $\begin{array}{l}\text { Arah pergerakan } \\
\text { Harga } \\
\text { saham }\end{array}$ & Naik Turun & Nominal \\
\hline 2. & Swing High & $\begin{array}{l}\text { Harga tertinggi } \\
\text { pada jangka } \\
\text { waktu tertentu }\end{array}$ & Rupiah & Rasio \\
\hline 3. & Swing Low & $\begin{array}{l}\text { Harga terendah } \\
\text { pada } \\
\text { jangka waktu } \\
\text { tertentu }\end{array}$ & Rupiah & Rasio \\
\hline 4. & Support Level & $\begin{array}{l}\text { Level harga } \\
\text { saham secara } \\
\text { historis, susah } \\
\text { untuk turun } \\
\text { lagi. }\end{array}$ & Rupiah & Interval \\
\hline 5. & $\begin{array}{l}\text { Resistance } \\
\text { Level }\end{array}$ & $\begin{array}{l}\text { Level harga } \\
\text { saham secara } \\
\text { historis, susah } \\
\text { untuk naik } \\
\text { lagi. }\end{array}$ & Rupiah & Interval \\
\hline 6. & Rekomendasi & $\begin{array}{l}\text { Rekomendasi } \\
\text { harga yang } \\
\text { diberikan oleh } \\
\text { analisis } \\
\text { teknikal dengan } \\
\text { fibonacci }\end{array}$ & $\begin{array}{l}\text { Jual, Tahan, } \\
\text { atau Beli }\end{array}$ & \\
\hline
\end{tabular}

\section{Pengolahan Data}

\section{Fibonacci Retracement}

Pengolahan data dengan Fibonacci Retracement dibantu menggunakan software ipotstock dari Indopremier. Penggunaan software Ipotstock untuk memudahkan dalam menentukan level support dan resitance. Penerapan level support dan resistance pada Fibonacci Retracement digunakan tujuh level.

\section{Stochastic Oscillator}

Indikator stochastic oscillator untuk menentukan level oversold ataupun overbought. Swing 
low berada pada titik 0\% jika trend menunjukan kenaikan dan digunakan sebagai swing high jika terjadi penurunan trend pada grafik. swing high pada titik $100 \%$ jika trend menunjukan kenaikan dan digunakan sebagai swing low jika terjadi penurunan trend pada grafik. hal ini berlaku untuk level lainnya dan akan mengikuti sesuai dengan urutannya.

\section{Analisis data}

1. Input Data

Data yang diinput adalah grafik pergerakan harga saham Food \& Baverage dalam Indeks JII BEI periode 2020. Pergerakan harga saham yang diambil sebagai sampel adalah pergerakan harga saham selama satu tahun periode 2019. Proses input data dilakukan dengan bantuan software Ipotstock dari Indopremier. Proses input data dilakukan secara online.

\section{Wawancara}

Wawancara dilakukan dengan karyawan dari sekuritas, Indopremier dan Profindo sekuritas. Hal ini dilakukan sebagai bentuk acuan dan referensi dari para ahli.

\section{Penggunaan Grafik Candlestick}

Data yang diinput merupakan grafik pergerakan harga saham. Grafik yang digunakan untuk menganalisis adalah grafik candlestick. Grafik candlestick dipilih karena informasi yang lebih lengkap dibandingkan grafik jenis lain. Selain itu juga, grafik candlestick mampu menyajikan informasi perdagangan saham melalui bagian tengah grafik.

4. Menentukan Trend Pergerakan Harga Saham dan Titik Swing High dan Swing Low. Setelah memperoleh data berupa grafik candlestick kemudian menetukan titik swing high dan swing low. Harga tertinggi yang diperoleh dalam grafik adalah titik swing high sedangkan, titik swing low diperoleh dari harga terendah dalam grafik. Setelah menentukan titik swing high dan swing low selanjutnya adalah identifikasi trend pergerakan harga saham. menentukan trend harga saham dilakukan dengan menarik garis lurus dan puncak-puncak dan lembah-lembah untuk mengidentifikasi kecenderungan pergerakan harga saham dalam grafik.

5.Menentukan Level Support dan Resistance. Setelah menemukan titik swing high dan swing low, selanjutnya dilakukan penginputan data dan diolah menggunakan pendekatan Fibonacci Retracement. hal ini dilakukan untuk menentukan level support dan 
resistance pada grafik. Pengolahan data dengan Fibonacci Retracement dibantu menggunakan software ipotstock dari Indopremier. Penggunaan software Ipotstock untuk memudahkan dalam menentukan level support dan resitance. Penerapan level support dan resistance pada Fibonacci

6. Menentukan Level Support dan Resistance Berdasarkan Trend Hasil pendekatan Fibonacci Retracement akan mengikuti trend yang terjadi pada pergerakan saham, ditambah dengan indikator stochastic oscillator untuk menentukan level oversold ataupun overbought. Swing low berada pada titik $0 \%$ jika trend menunjukan kenaikan dan digunakan sebagai swing high jika terjadi penurunan trend pada grafik. swing high pada titik $100 \%$ jika trend menunjukan kenaikan dan digunakan sebagai swing low jika terjadi penurunan trend pada grafik. hal ini berlaku untuk level lainnya dan akan mengikuti sesuai dengan urutannya.

\section{HASIL PENELITIAN DAN PEMBAHASAN (TIMES NEW ROMAN (TNR-12) BOLD)}

\section{Hasil Penelitian}

Fibonacci Retracement adalan tujuh garis yang digunakan dalam deret fibonacci. Sebelum menentukan level support dan resistance terlebih dahulu harus diketahui swing high dan swing low. Swing high merupakan candlestick yang tinggi dalam jangka pendek dengan setidaknya dua tertinggi lebih rendah pada sisi kiri dan kanan dari candlestick yang tinggi. Swing low merupakan candlestick rendah jangka pendek dengan setidaknya dua terendah lebih tinggi pada kedua sisi kiri dan kanan dari candlestick rendah. Titik swing high dan swing low juga mengambarkan trend yang tengah terjadi pada suatu saham. Rasio-rasio tersebut diperoleh dari perhitungan sebagai berikut:
a. $0,00 \%$ merupakan angka pertama dari deret Fibonacci
b. $23,6 \%$ merupakan $p h i-p h i^{2}$
c. $38,2 \%$ merupakan phi kuadrat
d. 50,0\% merupakan setengah dari 1
e. $61,8 \%$ merupakan phi
f. $78,6 \%$ merupakan akar dari phi
g. $100 \%$ merupakan nilai mutlak [2]

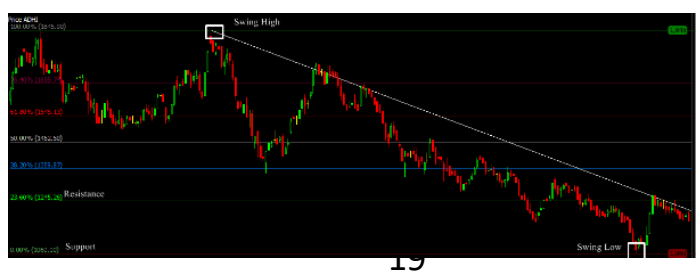




\section{Gambar 3. Level support dan resistance dengan rasio Fibonacci}

Sumber: Aplikasi Ipotstock Indopremier

Untuk mengukur harga relatif, tertinggi dan terendah selama suatu periode para investor juga dibantu dengan Stochastic Oscillator untuk menunjukkan posisi closing(Ramlall, 2016)Pada indikator Stochastic Oscillator, terdapat dua garis yaitu \%K dan \%D. Kedua garis ini menandakan harga akan naik atau turun. Keadaan oversold menurut Stochastic jika \%K dibawah 20 dan untuk overbought diatas 80 .

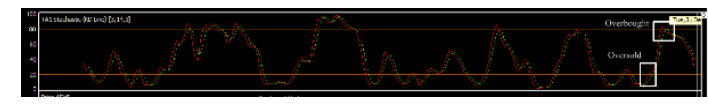

Gambar 4. Stochastic Oscillator

Sumber: Aplikasi Ipotstock Indopremier

\section{Pembahasan}

Analisa sahan ICBP, INDF, JPFA, dan UNRV dapat terlihat pada gambar 5,6,7 dan 8 beserta table 2, 3, 4, 5. Cara menganalisa saham ini adalah dengan melihat trend dari setiap grafik apakan naik atau turun dan menentukan titik support dan resistance. Dengan menari titik tersebut kita dapat memperkirakan harga saham dikemudian hari. Namun analisa teknikal ini hanya dapat dilakukan untuk analisa jangka pendek .

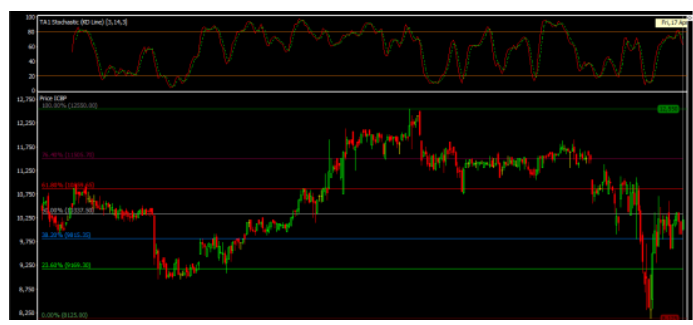

Gambar 5. Analisis Saham ICB

Tabel 2. Analisis Saham ICBP

\begin{tabular}{ll}
\hline Kode Saham & ICBP \\
\hline
\end{tabular}




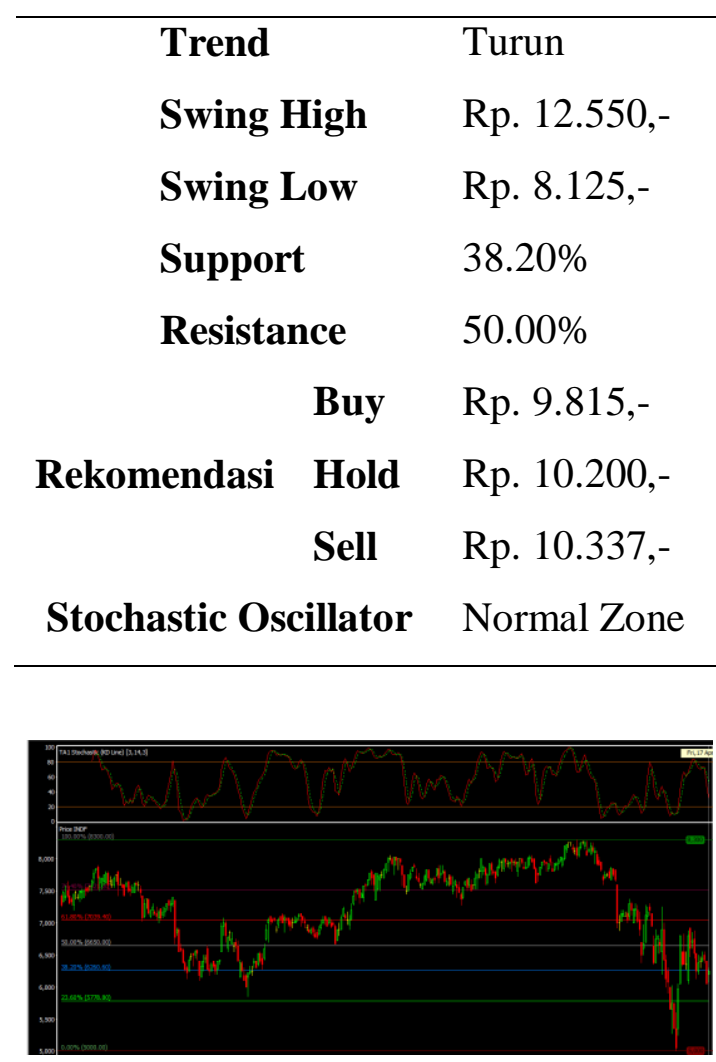

Gambar 5. Analisis Saham INDF

Tabel 3. Analisis Saham INDF

\begin{tabular}{cl}
\hline Kode Saham & INDF \\
\hline Trend & Turun \\
Swing High & Rp. 8.300,- \\
Swing Low & Rp. 5.000,- \\
Support & $23.60 \%$ \\
Resistance & $38.20 \%$ \\
Buy & Rp. 5.778,- \\
Rekomendasi Hold & Rp. 6.250,- \\
Sell & Rp. 6.260,- \\
Stochastic Oscillator & Normal Zone \\
\hline
\end{tabular}

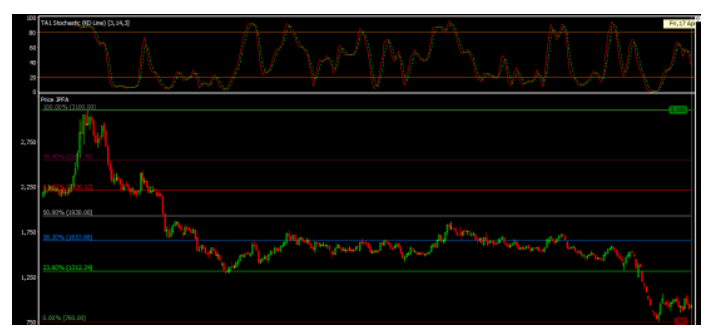


Gambar 6. Analisis Saham JPFA

Tabel 4. Analisis Saham JPFA

\begin{tabular}{|c|c|c|}
\hline \multicolumn{2}{|c|}{ Kode Saham } & JPFA \\
\hline \multicolumn{2}{|l|}{ Trend } & Turun \\
\hline \multicolumn{2}{|c|}{ Swing High } & Rp. 3.100,- \\
\hline \multicolumn{2}{|c|}{ Swing Low } & Rp. 760,- \\
\hline \multicolumn{2}{|c|}{ Support } & $00.00 \%$ \\
\hline \multicolumn{2}{|c|}{ Resistance } & $23.60 \%$ \\
\hline \multirow{3}{*}{ Rekomendasi } & Buy & Rp. 760,- \\
\hline & Hold & Rp. 930,- \\
\hline & Sell & Rp. 1.312,- \\
\hline \multicolumn{2}{|c|}{ Stochastic Oscillator } & Normal Zone \\
\hline
\end{tabular}

Gambar 7. Analisis Saham UNVR

Tabel 5. Analisis Saham UNVR

\begin{tabular}{ll}
\hline Kode Saham & UNVR \\
\hline Trend & Turun \\
Swing High & Rp. 10.105,- \\
Swing Low & Rp. 5.275,- \\
Support & $23.60 \%$ \\
Resistance & $38.20 \%$ \\
Buy & Rp. 6.414,- \\
Rekomendasi $\quad$ Hold & Rp. 6.875,-- \\
Sell & Rp. 7.120,- \\
\hline
\end{tabular}




\section{Stochastic Oscillator Normal Zone}

\section{Hasil}

Seluruh saham sektor makanan dan minuman pada JII 2020 mengalami trend menurun. Level support dan resistance yang dimiliki oleh saham sektor makanan dan minuman pada JII secara umum berbeda-beda, kecuali saham INDF dan UNVR yang sama yaitu level support di $23.60 \%$ dan resistance di angka $38.20 \%$. Dengan menggunakan stochastic oscillator seluruh saham food and beverage pada LQ45 dan JII berada pada titik normal, yaitu diangka 20-80 pada indikator stochastic oscillator. Hasil analisis teknikal menyatakan saham ICBP adalah yang kinerjanya paling baik dengan menggunakan fibonacci dan indikator stohastic oscillator.

\section{KESIMPULAN DAN IMPLIKASI}

Berikut adalah kesimpulan dari hasil analisis saham sektor makanan dan minuman pada LQ45 dan JII 2020:

1. Seluruh saham sektor makanan dan minuman pada LQ45 dan JII mengalami trend menurun.

2. Level support dan resistance yang dimiliki oleh saham sektor makanan dan minuman pada LQ45 dan JII secara umum berbeda-beda, kecuali saham INDF dan UNVR yang sama yaitu level support di $23.60 \%$ dan resistance di angka $38.20 \%$.

3. Dengan menggunakan stochastic oscillator seluruh saham food and beverage pada LQ45 dan JII tahun 2020 berada pada titik normal, yaitu diangka 20-80 pada indikator stochastic oscillator.

4. Rekomendasi harga saham ICBP Rp. 10.200,- adalah hold, buy pada harga Rp. 9.815,- dan sell pada harga Rp. 10.337,-. Rekomendasi harga saham INDF Rp. 6.250,- adalah hold, buy pada harga Rp. 5.778,- dan sell pada harga Rp. 6.260,-. Rekomendasi harga saham JPFA Rp. 930,- adalah hold, buy pada harga Rp. 760,- dan sell pada harga Rp. 1.312,-. Rekomendasi harga saham UNVR Rp. 6.875,- adalah hold, buy pada harga Rp. 6.414,- dan sell pada harga Rp. 7.120,-.

Adapun saran yang perlu disampaikan sebagai berikut:

1. Hasil analisis teknikal menyatakan saham ICBP adalah yang kinerjanya paling baik dengan menggunakan fibonacci dan indikator stohastic oscillator. 
2. Perlunya penambahan analisis menggunakan analisis fundamental agar hasilnya semakin sempurna untuk mengambil keputusan investasi jangka panjang.

3. Penelitian ini dapat dijadikan pertimbangan untuk keputusan investasi.

\section{DAFTAR PUSTAKA (TIMES NEW ROMAN}

Ardani, N., Murhadi, W. R., \& Marciano, D. (2011). Investasi: Komparasi Strategi Buy and Hold dengan Pendekatan Teknikal. Jurnal Akuntansi Dan Keuangan, 14(1). https://doi.org/10.9744/jak.14.1.32-44

BHANDARI, B. (2014). Fibonacci and stock analysis. Futures: News, Analysis \& Strategies for Futures, Options \& Derivatives Traders.

Bortner, C., \& Peterson, A. (2016). the History and Applications of Fibonacci Numbers. UCARE Research Products.

Fisher, R., \& Fisher, J. (2003). Candlesticks, fibonacci, and chart pattern trading tools. In TA Book.

Marshall, B. R., Young, M. R., \& Rose, L. C. (2006). Candlestick technical trading strategies: Can they create value for investors? Journal of Banking and Finance, 30(8), 2303-2323. https://doi.org/10.1016/j.jbankfin.2005.08.001

Mohammad. Alalaya, D. (2018). Fibonacci Retracement and Elliot Waves to Predict Stock Market Prices: Evidence from Amman Stock Exchange Market. International Journal of Applied Science and Technology. https://doi.org/10.30845/ijast.v8n3p7

Rahmawati, N., Ag, M., Jemen, M., Yusup, M., \& Si, M. (n.d.). Mana jemen investasi syariah.

Ramlall, I. (2016). Applied Technical Analysis for Advanced Learners and Practitioners. In Applied Technical Analysis for Advanced Learners and Practitioners. https://doi.org/10.1108/9781786356338

Riska Farisa, B. M., Prayitno, G., \& Dinanti, D. (2019). Social Capital and Community Participation on Infrastructure Development in Pajaran Village, Malang Regency Indonesia. IOP Conference Series: Earth and Environmental Science, 239(1). https://doi.org/10.1088/1755-1315/239/1/012046 